\title{
Liberian man being treated for Ebola in Texas dies
}

\author{
Michael McCarthy \\ Seattle
}

A Liberian man who fell ill with Ebola shortly after arriving in the United States has died, officials at the Texas hospital where he was being treated announced on Wednesday 8 October.

Thomas Eric Duncan, a 42 year old Liberian national, left Liberia on 19 September, arriving in Dallas, Texas the next day. ${ }^{1}$ Press reports said that he had helped to carry a young woman who was ill with Ebola several weeks earlier but had not had symptoms of infection while en route to the US. Liberian health officials have said that Duncan was screened before boarding the flight but that he denied exposure to anyone ill with the infection.

On 24 September, four days after he arrived in Dallas, Duncan sought care at the emergency department at Texas Health Presbyterian Hospital of Dallas, a large, acute care community hospital. There he reported that he had had abdominal pain for two days, a sharp headache, and decreased urination. His temperature was $100.1^{\circ} \mathrm{F}\left(37.8^{\circ} \mathrm{C}\right)$.

The hospital said that Duncan was asked whether he had been around anyone who was ill and that he said he had not, although he did disclose that he had recently been in Africa. Nevertheless, Duncan was discharged and sent home.

Two days later, now severely ill, Duncan was brought to the hospital by ambulance and admitted to an isolation unit. Because of his symptoms and travel history, specimens were sent to a laboratory at the US Centers for Disease Control and Prevention in Atlanta, as well as a Texas laboratory that is part of the

centre's Laboratory Response Network. On 30 September the diagnosis was confirmed as Zaire ebolavirus. It was the first time that a case of Ebola had been diagnosed in the US and the first time that Zaire ebolavirus had been diagnosed outside Africa.

Duncan's condition worsened, he required ventilator support, and he underwent renal dialysis. Over the weekend he was started on an experimental drug, brincidofovir-an oral nucleotide analog that had been shown to be active in vitro against Ebola. However, he died at 751 am on Wednesday.

"He fought courageously in this battle," the hospital said in a statement announcing Duncan's death. "Our professionals, the doctors and nurses in the unit, as well as the entire Texas Health Presbyterian Hospital Dallas community, are also grieving his passing. We have offered the family our support and condolences at this difficult time."

Texas health authorities are monitoring 48 people for signs of infection; 10 of the 48 are known to have been in contact with Duncan, and the remaining 38 are considered to be possible contacts. None has been reported to show signs of infection.

1 McCarthy M. Obama calls on other nations to step up their efforts to end Ebola outbreak. BMJ 2014;349:96094.

Cite this as: BMJ 2014;349:g6145

๑ $\mathrm{BM}$ J Publishing Group Ltd 2014 